\title{
Qualitative Secondary Analysis as an Alternative Approach for Cross-Cultural Design
}

\author{
A Case Study with Saudi transnationals
}

\author{
Taghreed Alshehri \\ Taif University, Taif, Saudi Arabia \\ tagreed.s@tu.edu.sa \\ Reuben Kirkham \\ Inclusive Technologies, Monash University, Melbourne, \\ Australia \\ reuben.kirkham@monash.edu
}

\begin{abstract}
It is widely acknowledged in HCI that culture is embodied in many aspects of an individual's identity and interaction with technology. Whilst existing cultural models have been criticized for providing a deterministic view of culture, alternative methods for incorporating culture in design remain scarce. We introduce the use of Qualitative Secondary Analysis (QSA) as a bottom-up approach to construct a richer and more dynamic understanding of culture to inform our best practices in Cross-Cultural Design. We demonstrate the use of QSA within a culturally specific context, namely Saudi transnationals. We draw upon two case studies (with 55 participants) to investigate the cultural factors underpinning our participants views. We conclude with a reflection on key affordances and challenges of QSA, illustrating how QSA can be leveraged to unravel otherwise overlooked knowledge present in many qualitative HCI studies.
\end{abstract}

\section{CCS CONCEPTS}

- Human-centered computing; • Interaction design; • Interaction design process and methods;

\section{KEYWORDS}

Culture, Cross-Cultural Design, Qualitative Secondary Analysis (QSA)

\section{ACM Reference Format:}

Taghreed Alshehri, Norah Abokhodair, Reuben Kirkham, and Patrick Olivier. 2021. Qualitative Secondary Analysis as an Alternative Approach for Cross-Cultural Design: A Case Study with Saudi transnationals. In $\mathrm{CHI}$ Conference on Human Factors in Computing Systems (CHI '21), May 0813, 2021, Yokohama, Japan. ACM, New York, NY, USA, 15 pages. https: //doi.org/10.1145/3411764.3445108

\footnotetext{
(c) $(\oplus)$ 4.0 License.

CHI '21, May 08-13, 2021, Yokohama, Japan

(c) 2021 Copyright held by the owner/author(s).

ACM ISBN 978-1-4503-8096-6/21/05.

https://doi.org/10.1145/3411764.3445108
}

This work is licensed under a Creative Commons Attribution-NoDerivs International

\author{
Norah Abokhodair \\ Microsoft, Seattle, USA \\ noraha@microsoft.com \\ Patrick Olivier \\ Action Lab, Monash University, Melbourne, Australia \\ patrick.olivier@monash.edu
}

\section{INTRODUCTION}

Humans are cultural beings. The prolonged and interpersonal relations between individuals result in the creation of shared traits and values, collectively referred to as culture $[15,17,57]$. As such, culture becomes embodied in many aspects of the individual's identity, perceptions and behavior $[64,65]$. Understanding the influence of culture on individuals' technology-related beliefs and behavior has been an increasingly important concern in design [54]. In design work, researchers have debated on two approaches to understand culture [48]: either to focus on culture from deep and rich fieldbased approaches such as ethnographies of specific phenomena or to address culture from the perspective of overarching and aggregate approaches such as cultural models (e.g. Hofstede's [33]). While ethnography is associated with methodological challenges relating to access, time, cost and resources; cultural models are quantitative approaches based on pre-defined dimensions which may sacrifice cultural richness and specificity [48]. Nonetheless, Hofstede's and other cultural models are still predominant in cross-cultural design.

Typically, cultural models define culture in a set of cultural dimensions/values [4]. They view culture as an objective entity with universal, quantifiable cultural dimensions representing independent variables; best used for cultural comparison [48, 75]. Overreliance on these models can, in part, be attributed to the difficulty associated with conducting richer interpretive approaches such as ethnography [48]. Although such models are pragmatic and structured for studying and comparing cultures [34], they have been criticized for viewing culture as a fixed set of rules [65] and thus perpetuating stereotypes rather than highlighting distinctive attributes of culture [20]. As such, there are subtle elements specific to a given culture that may not be captured in these models. Such limitations are paramount in cultural work related to underrepresented and/or elusive groups; especially given that the access to these groups may be limited, with the knock-on effect of them being excluded or poorly represented by existing dimension or value-based models.

In response, we propose Qualitative Secondary Analysis (QSA) as an alternative approach to transcend the limitations of both time and resource intensive ethnographies and universal models of culture. The proposed approach combines benefits from the richness and specificity gained from ethnography with the pragmatism of conceptualizing culture as a set of dimensions offered by cultural models. In adopting QSA, data produced from previous studies 
with culturally specific groups can be re-used to establish an overall cultural understanding beyond the purpose of the primary (original) study. We thus argue that the missing cultural knowledge of understudied populations might well be hidden in much of the under-utilized qualitative data produced in primary investigations.

Drawing on our joint work of two independent case studies with a culturally specific group (55 Saudi transnationals), we provide both an account of, and a critical reflection on, leveraging QSA for cross-cultural design. We suggest and demonstrate that this approach is intended to complement and expand upon rather than replace the established 'top down' use of cultural models. By topdown we refer to deterministic approaches in which dimensions are pre-defined and universal - in these top-down models, all cultures are described using these pre-defined dimensions by being given specific numerical scores under each dimension. In contrast, bottomup approaches refer to subjective constructions of culture where dimensions are culturally specific (not universal) because they are derived from culturally specific studies and populations, as opposed being pre-defined in advance.

We emphasize the significance of bottom-up approaches in giving a voice to cultural groups that are underrepresented, hard to reach, or systemically marginalized. We demonstrate this in our study with a population representing an emerging (understudied) segment in Saudi culture.

The purpose of this paper is twofold: the main goal is to propose QSA as a bottom-up approach for cross-cultural design, whilst the secondary goal is to illustrate this with a culturally specific group (i.e. Saudi transnationals). The contribution of this work goes beyond the use of QSA itself, but in applying and adapting QSA as a bottom-up approach to learn about the specificities of cultures, thereby generating cultural dimensions in cross-cultural design as a means to address the already recognized limitations of the two predominant approaches in cultural studies, namely ethnographies and top-down cultural models.

In the sections that follow, we extend the debate around approaching culture in design work by proposing and examining Qualitative Secondary Analysis (QSA) as an alternative approach. We review its possibilities and pitfalls and what it has to offer for cross-cultural design (and HCI more broadly). We then present our case studies, and our cultural insights of the population under study. Finally, we conclude with a reflection and implications for cross-cultural design.

\section{BACKGROUND AND RELATED WORK}

Before presenting our proposal of using QSA in cross-cultural design, we first present the concept of culture and how different models have attempted to define it - usually by way of creating top-down models. We discuss the limitations of these cultural models and emphasize the need to address these limitations particularly when working with underrepresented groups. We review previous related work in design and introduce the cultural context of our study. We discuss the need for an approach to explore the cultural specificity in different contexts, especially in respect of understudied groups. For this we propose a method addressing the cultural model's limitations by using a bottom-up approach (which we present in Section 3).

\subsection{Understanding Culture}

Scholars have provided many different definitions of culture, ranging from descriptive, historical, normative and psychological [17]. By 1952, over 160 definitions of culture were noted in the collection of Kroeber and Kluckhohn [42, 52]. Perhaps the most widely adopted definition in the cross-cultural design literature is that of Hofstede [33]. Hofstede defined culture as "the collective programming of the human mind that distinguishes the members of one human group from those of another." [33]. This collectiveness refers to the shared meanings, patterns, norms, values, behavior and practices among members of a cultural group [55, 71]. Culture and individuals' behavior are inseparable [17], although the difference between the two should not be overlooked. The collective nature of culture is above and beyond the individual person [17]. Much as personality shapes the identity of an individual, culture shapes the identity of a group [33, 64]. Culture is supra-personal and distinct from (and dominant over) individual and society; it is more than the sum of its parts [57]. As such, culture does not fully fuse all members of a cultural group into one, nor it resides "fully in the head" of a member of that group [62]. Rather, culture exists to represent the collective and to respond to individuals' biological, psychological and social needs [57]. In that sense, culture provides solutions to facilitating, regulating and sustaining human individuals' connection to (or deviance from) wider society over time [57, 62]. Given the complexity inherent in the concept of culture, a series of cultural models have been developed to help provide a better understanding of this phenomena.

\subsection{Cultural Models}

To better understand culture, a series of national culture models have attempted to help simplify the abstract and complex nature of culture [55, 64]. Notable models include those of Hall, Hofstede and Trompenaars (these are compared and contrasted in [68]). Hall provided a high-level classification of cultures as either low context or high context with a specific characteristic for each type [37]. Hofstede developed a more sophisticated model constituting of six cultural dimensions (e.g. collectivism, masculinity) against which countries are characterized and measured. For example, a culture with a high score (out of 100) on the collectivism dimension would be classified as a collectivist culture. In a similar vein, Trompenaars' model [74] consisted of seven dimensions, each dimension is presented in a spectrum between two values (e.g. universalism vs. particularism, neutral vs. emotional).

Despite having been proved to be helpful for high-level analysis and cross-cultural comparison, these models have been criticized for their overly simplistic treatment, and static view of culture $[70,71]$. The challenge remains that culture is an ever changing concept, and thus, it is dynamic, open-ended and not easily captured in static models of culture [70]. Moreover, the modus operandi of these models takes a top-down approach where a unified set of dimensions is predefined and then quantitatively measured across cultures. As such, other specific cultural dimensions may not be represented within these universal pre-defined sets of dimensions. This lack of "specificity" has been acknowledged in cross-cultural design as a common problem that designers face when adopting cultural models. 
In response, the notion of defining culture from the bottom up as a subjective construct (instead of an objective one) has started to gain prominence in the past decade [75]. This view sees culture as being relational to other cultures and focuses on the subjective cultural sensemaking of the involved actors through micro-level examinations, which in turn are used to provide insights into the construction of cultural specificity [75]. For instance, Tukiainen called for advocating individual volition and cultural agency where individuals are viewed as capable of counteracting cultural forces rather than being merely "dopes" of culture [75]. Similarly, KaarstBrown and Guzman proposed an approach towards understanding culture from multiple perspectives [48]. In line with these subjective approaches to culture, we hope to move this debate further by considering an alternative and pragmatic approach to define culture from the ground up.

\subsection{Culture in Cross-Cultural Design}

With the global increase in Internet and smartphone use, there has been a growing interest in the study of cultures within the design of technology (i.e. cross-cultural design) [55, 64]. Thus, the accommodation of users' cultural backgrounds in the design process has been widely considered in the field of $\mathrm{HCI}[14,28,31,44,45,51]$. The requirement to localize digital products and services, to adapt them to meet the cultural expectations of different target groups [55], has highlighted the need for processes by which designers can gain awareness of often-nuanced culture-specific contexts [69, 70, 77]. However, describing culture remains a complicated endeavor and adopting the top-down national culture models (e.g. Hofstede, Hall) does not provide a space for exploring the specificity of each culture, as discussed earlier.

Localizing the design of technology for different cultures remains a significant challenge, in large part due to the lack of methods for operationalizing the implications of abstract cultural theories as concrete design decisions [55]. Cross-cultural researchers still face many methodological challenges including access to diverse populations, sampling, analysis and interpretation [41], and above all defining and assessing culture. These challenges can be observed in much of the work in cross-cultural design being focused on either visual level issues [69] (e.g. colors, languages, images and cultural markers) or predefined cultural dimensions in cultural models [71, 72]. To address this, Sun [70] suggests that there is a need to develop a rhetorical approach to guide the design process based on thorough context analysis; an approach with a richer and more dynamic view of culture [71]. Likewise, Amant [69] suggests that designers have to focus on gaining deeper knowledge about cultural contexts, and to adopt a strategic approach to learn about the multifaced concept of culture, beyond simply conducting a literature review of existing cultural studies. In the specific cultural context of our joint work with Saudi individuals living abroad (which we term 'transnational Saudis'), only a few studies have attempted to establish a relevant cultural understanding.

\subsection{Cross-Cultural Design in the Arab Context}

Arab countries have received little attention in cross-cultural design studies [61]. To date, few studies of the region have been configured as theoretically grounded investigations of specificity and nuances of Arab cultures. Studies conducted to date have primarily undertaken content analysis of social media, without significant involvement of target users to understand their values or needs [51]. Since the Arab upheaval in 2011, many different platforms have been utilized as mediums to express opinion and to call for equal rights [5]. For instance, it has been found that Facebook enhanced the ability of activists and protesters to coordinate peaceful protests, while allowing larger segments of the public to share witness accounts, images and videos [49]. Yet little research has been undertaken into users' daily interactions and experiences with these technologies and services, or the opportunities and challenges they bring in terms of managing personal identity, privacy and safety.

$\mathrm{Al}$ Omoush et al. [61] introduced a model for the relationship between cultural values, motivations, and usage patterns on Facebook in the Arab world. Their study revealed a major influence of Arab values (e.g., cultural traditions and religion) on Arab Facebook users and their motivations to be members of social media. In this line of enquiry, many researchers treat the "Arab world" as a single monolithic unit of analysis, which is regrettably a misleading and inaccurate generalization. Critiquing Al Omoush et al.'s study, Ur and Wang [82] state that "[the authors] used snowball sampling to gather survey responses from 749 Arab users of Facebook, where the exact meaning of Arab is left ambiguous". Similarly, a study by Alsheikh et. al. [14] explored how Arab individuals conceptualize and employ technologies in their romantic relationships. The participants came from six Arab countries and had different religious backgrounds. While their study provided high-level insights into the values of the region; it demonstrated a limited understanding of the diversity of the participants. Alshehri et. al [12] developed a culturally sensitive method for eliciting values based on the argument that "values are inherently cultural" and thus values should be understood and investigated within the cultural specificity of their context.

Taking a broader view, other works have explored the notion of Eastern values versus Western values (e.g. [29] and [63]) and a number of studies have explored cultural values in specific countries in the Arab world, such as Kuwait [30], Morocco [77], Jordan [51] and Qatar $([1,66,79])$.

With respect to Saudi culture, Hofstede's model has mostly been utilized to explore cultural values in the context of business, government and organizational e-services (e.g. [9, 11, 13, 39]). Based on Hofstede's dimensions, Saudi Arabia, is characterized by high power distance, uncertainty avoidance, masculinity, indulgence, short term orientation and collectivism [43]. However, as discussed earlier, Hofstede's model was originally devised for cross-cultural comparison and not for unpacking the specificity and nuances within a given culture. This is particularly relevant in the Saudi context, where there is a distinctive mix of cultural features such as religious nationalism, tribalism, Bedouin culture and the absence of anti-colonial struggle or secular movements [10]. A number of qualitative studies have sought to elaborate specific cultural aspects, such as the importance of religion in Saudi Arabia and the influence of Islamic values and cultural traditions on perceptions of privacy [3], and cultural factors influencing perceptions and use of matchmaking technologies [8]. However, each of these studies had a specific focus (e.g. privacy, matchmaking, etc.) and did not capture wider insights regarding the cultural context. 
In response, building on the same modus operandi of the cultural models, we define culture in a set of dimensions. However, we address the lack of cultural specificity (in top-down models) by taking a bottom-up approach where dimensions emerge from the data of studying culturally specific groups, as opposed having been pre-ordained in advance. We also address the static view of culture (in cultural models) by presenting each of our dimensions in a spectrum rather than a specific numerical value. The notion of spectrums is similar to that in Trompenaars' model [74], however, Trompenaars's spectrum classified different cultures on different points of the spectrum (a more deterministic approach); whereas we acknowledge the diversity within each specific culture thus our spectrums represent the diversity within individuals (a nuanced approach). By doing so, we encourage designers to adopt such an approach for culturally specific investigations. We propose QSA as a potential approach to achieve this goal.

\subsection{Cultural Background and Population of the Study: Saudi Arabia \& Transnationalism}

After September 11, 2001 - and the subsequent terrorist events in Saudi Arabia- the Saudi state was severely shaken [10, 84]. Since then, human rights reports have started to put increased pressure on the Saudi state to seek a more inclusive policy and legitimacy abroad [10]. As such, the state has introduced policies fighting "terrorism" and "extremism" and promoting "reformism", "moderation" and "tolerance" [53]. This has also been accentuated after the Arab uprising of 2011. Despite being relatively stable, and the MENA country least affected by the Arab upheavals, Saudi Arabia has received increased demands for political and social reforms [32]. Most of these demands were not revolutionary, as many believed that the government, particularly King Abdullah at the time, was making the necessary reforms, or even making more and faster reforms than what the Saudi society is prepared to accept [25].

As eager as it is to appear modern, the Saudi state is aware of potential internal conflict with its religious establishment [10,25]. The reform has created internal ongoing debates between voices of conservatism and modernization [84]. The Saudi state has therefore been gradually introducing reforms whilst struggling to create an alternative form of modernity to the globalized one [10]. Such an alternative perhaps is expressed in what the Saudi state has started promote as moderate Islam [59]. This provides a framework under guidance of the religious scholars to minimize potential backfire, social chaos or antagonizing religious scholars whose defense is needed at times of political crises $[10,25,80]$. The reforms introduced to "remake the nation" have focused on particular groups that are anticipated to have a great influence of the ongoing cultural change $[53,80]$. One particular such group is transnational Saudis. The Saudi government invests over $\$ 2$ billion annually under the King Abdullah Scholarship program (KASP) to sponsor Saudi students abroad [6]. This has been the biggest factor creating the sociocultural group of transnational Saudis. KASP is one of the strategies to drive the "moderation" movement by pursuing cultural exchange and exposing young Saudis to other cultures and create more open minded future generations [58, 85]. Despite their rapid increase and their evident cultural change, transnational Saudis have yet to be examined as an influential group in their role in creating or embodying cultural changes upon their return [6].

Although the benefits of studying abroad in general have been examined [85], the gains and socio-economic impacts particular to Saudi transnationals are more challenging to track [76]. The potential difficulties of studying this group include their geographical distribution and their relatively conservative home culture [58], the latter of which in turn may make them hard to reach, or have a 'chilling effect' on discussion of sensitive cultural or political topics. This means that obtaining access to this group and then unpacking of their cultural values with minimum intrusion may prove to be a challenging endeavor for researchers. Therefore (alongside other understudied populations) - working with such groups could be better facilitated by the use of (more tacit) bottom-up approaches to gain culturally sensitive and relevant insights [73] which in turn can address the limitations of universal cultural models and improve our practices in cross-cultural design.

Another factor shaping the identity of this population is their migration and dual-cultural experience. Population migration is a widely recognized phenomenon which requires individuals to change different aspects of their lives [7, 78]. The acculturation process in the new environment is dealt with by adopting a number of different strategies [16]. The distinctions between individuals' origins and their acquired identity have been characterized as a new form of identification referred to as transnationalism [24]. Transnationalism is the dual sense of identity, ties and interactions connecting people across the borders of nations [78]. Transnationals undergo construction of dual identity, where different facets of culture are often self-consciously selected from more than one cultural heritage [78]. This is a process takes conscious decisions about what aspects of culture to change (or not). These decisions can involve the loss of the previously familiar, including language, attitudes, values and social structures [18]. In acquiring this ability to make cultural change themselves, transnationals are also considered to be agents of cultural changes within their communities of origin when they return home [24]. Transnational migrants are believed to have a central role in effecting cultural change in their families, societies, populations, surrounding transnational networks and post-migration generations [24, 78]. As such, we recognize transnational populations as a highly valuable source of insight for cross-cultural design. We thereby present valuable cultural insights we learned from working with a transnational population.

\section{QUALITATIVE SECONDARY ANALYSIS (QSA)}

\subsection{Conducting QSA}

Qualitative Secondary Analysis (QSA) is an empirical exercise conducted by the re-use of existing data - produced in previous (primary) studies - in order to find answers to new (secondary) research questions that differ from the original questions asked in the primary research $[26,40,47,56,73]$.

What differentiates QSA from similar approaches (such as document analysis) is the type of data being reused [40]. QSA aims solely at reanalyzing non-naturalistic data, which refers to data solicited 
for (primary) research studies, whereas document analysis can include naturalistic data which was not originally generated with any research purpose in mind (e.g. day-to-day business records) [40].

QSA can encompass different approaches, including supplementary analysis (most common), amplified analysis, supra analysis, assorted analysis; and re-analysis (least common) [40]. We focus on supplementary analysis, which examines themes or aspects of the data which were not addressed in depth by the primary analysis; it thus aims to raise relevant additional research questions to extend upon the original work [40].

In this case, the secondary analysis aims to fulfill different purposes ranging from answering new research questions, performing additional analysis, adding a new conceptual focus, onto revealing new methodological insights, exploring themes that were not originally taken up for investigation, questioning/verifying primary findings and synthesizing studies [40, 47, 56, 67]. In this work, our purpose was to answer a new question, which is the most common purpose motivating the use of QSA [40]. The advantages of QSA discussed in the literature shed light on the potential of having the filed notes that are long buried in the researcher's files, to be reanalyzed from a new point of view in order to glean new conceptual or methodological insights [40,47]. Indeed, it has been recognized that qualitative datasets have much to offer beyond answering the primary research questions, to explore aspects that may have never been analyzed [56].

On epistemological and ethical grounds, it has been argued that the secondary analysis can generate rich insights on contemporary and historical attributes of specific individuals, populations or societies [56]. As such, QSA can be applied to address a sensitive research topics and to access elusive and underrepresented populations, without conducting new studies (with the delay and other difficulties this causes) [73]. While researchers typically draw on conceptual frameworks from existing literature, to understand the research context [73], such literature may not be sufficient to understand the cultural context of underrepresented groups. For this, QSA has been suggested as a strategy to navigate and reveal profound socio-cultural factors underpinning the participants experiences [26, 47]. Particularly, it is suggested that QSA can contribute to the existing narratives in the literature by providing alternative narratives to enhance our understanding of topics or populations that are mis- or under-represented, or simply hard to reach without further intrusion [47, 67].In alignment with these suggestions, we propose the use of QSA as a method for understanding culture whilst using the modus operandi of the typical cultural models.

Others have argued for QSA on pragmatic grounds by observing that qualitative research is time consuming and "data[sets] should be re-used, not least because they are expensive to produce" (p. 602) [73]. QSA can offer a cost-effective way to maximize insights from existing research and under-utilized data [26]. Typically, qualitative researchers engage in prolonged contact with participants in the field and produce relatively unstructured, abundant, rich, in-depth and diversified datasets $[40,47,67]$. Thus, there will often be a certain amount of the collected qualitative data that may never be used or analyzed in subsequent analyses, or at least presented in the published work $[47,56]$. This means that qualitative research has the capacity to enable greater use of qualitative data and generate extensive contextual narratives beyond the primary focus, which in turn creates a profound opportunity for conducting a secondary inquiry to leverage the existing data [47, 67].

\subsection{Challenges Related to Conducting QSA}

Alongside recognizing the benefits of QSA, some commentators have emphasized the difficulties of conducting QSA [38] and raised various epistemological and ethical issues [73]. While these issues are important to bear in mind, many other writers have emphasized the value of re-use and secondary analysis [47]. It is argued that such issues can arise in any research approach (as opposed being unique to QSA) and they are not insurmountable in a cautious and critical conduct of QSA [26, 38, 40, 47, 56, 73].

3.2.1 The Problem of Researcher Fit (Not Having 'Been There'). By its very nature, qualitative inquiry emphasizes 'seeing through the eyes of' the people under study', describing social behavior and reflecting on social contexts [40]. The researcher-participant relationship is considered an essential component influencing how the data is analyzed [56, 73]. Similarly, the lack of familiarity with the context and participants of the study can magnify the complexity of conducting a secondary analysis [73]. As such, a fundamental challenge of QSA is that data does not exist independently from the research context in which it was collected, and "if all that is available to the [secondary] researcher is the transcribed transcripts, then what the participant [truly] means may be lost" (p. 8) [56]. What is more, during data collection in qualitative studies, not everything can be written down, and even things that are written down are sometimes not included in data archives [38]. Thus, the researcher's absence from the research context has raised the vexed question of how this affects their interpretation of the material [40, 47].

Another common issue associated with the re-use of existing qualitative data is the problem of maintaining privacy for participants when researchers (other than the primary ones) conduct the secondary analysis. Indeed, it is difficult to maintain anonymity in qualitative data. The process of preparing data to be used by secondary analysts is complex, ethically demanding and timeconsuming [26]. For instance, anonymizing textual data produced by qualitative methods not only is costly and time consuming, but also makes it still possible to identify participants through the narratives and social contexts provided in their accounts [40, 56]. Other stored forms of qualitative data such as audio and visual data present even more difficulties for anonymizing and sharing data. Thus, as Heaton argued, efforts to anonymize participants' identities may distort the meaning and the context of the data [40]. The secondary analysis, thus, raises a number of issues about its compatibility with the nature of the qualitative methodology, mainly the researcher's awareness of the context and the privacy issues when sharing qualitative data.

To address these issues, it has been suggested that QSA is best (or should only be) conducted by the same (primary) researchers who collected the original data and interacted with the participants $[40,56]$. This is what Heaton [40] terms auto-data whereby the researcher re-uses their own data, possibly in conjunction with independently generated data, as a strategy for QSA to address a lack of access to contextual data [26,47]. Otherwise, it is suggested that the primary researchers should remain central in making decisions 
and assisting secondary analysts by offering feedback and evaluation of the re-used data [26]. Conversely, Irvin and Winterton [47] have argued that there is an over-privilege and an idealized conception of the original researcher's knowledge of contextual data which assumes that what a primary researcher 'knows' is always right. Instead, they argue for the potential benefits and validity of distance from the original research context which could "go beyond" the situated nuances and reveal fresh insights [26, 47]. A third position argues that neither proximity nor distance can provide greater or lesser validity or efficacy to the analysis [47]. Whether primary or secondary, the interpretation of data is always constructed and depends upon the researcher's viewpoint, and thus can "go astray" [38]. Additionally, the problem of proximity/distance, as Hammersley [38] argued, is not necessarily a severe one, nor is it peculiar to secondary analysis [38].

3.2.2 The Problem Of "Data Fit" (Answering New Questions). A common and well-rehearsed concern related to QSA is the potential lack of fit between the data available and the purposes of a secondary analysis $[38,40]$. Some scholars believe it is impossible to meaningfully transport qualitative data into new research contexts or to generate new theoretical advances beyond methodological insights [26, 47]. Whilst others argue that the secondary analysis remains closely aligned to the primary analysis and the secondary analysis is somewhat constrained by the primary analysis. [47]. In that sense, doing a secondary analysis does not mean that the available data is entirely malleable, rather the notion of re-using data imposes a constraint (and thus a form of guidance) as to what questions can be addressed, on the basis of the available data [38]. The problem of data fit therefore is connected with the degree of divergence between the primary and the secondary questions.

To address the issue of 'data fit', it has been suggested that the secondary research questions have to be sufficiently close to the primary questions, or even generated from the primary analysis [56]. It is also suggested that treating data as freestanding is problematic and thus secondary analysts should not only draw on the raw data but also the analysis and reports generated in the primary research [26]. Others, however, have rejected the proximity argument on the basis that it grants a certain amount of privilege to the primary analysis and treats data as 'given' [26, 38, 40]. They argue that it can constrain the generation of fresh insights; and suggested the success of QSA is mainly contingent on its objectives [47]. As early as 1963, Barney Glaser suggested that the conduct of a secondary analysis by an independent researcher could offer new strength to the resulting social knowledge [36]. A third perspective emphasizes that 'data' has two meanings: constructed and given, and that both are essential and should be retained in the secondary analysis [38, 47]. This means while secondary analysts should maintain some level of proximity to the primary analysis, they nonetheless should remain open and allow for a new perspective to be constructed.

3.2.3 The Problem Of Time And Context Change. It is assumed that qualitative analysis is 'normally' situated in the context in which the data was collected [56]. However, even when the same researchers return to their data for a secondary analysis, there is a chance they would experience a sense of dislocation from the original context [47]. After the passage of time, the data collected may even seem alien to the researcher in some respects and could be affected by their waning memory of the fieldwork [40]. What changes in the researchers' social status, views and expertise overtime may shape their interpretation differently based on the stance that cultural knowledge is context-bound [40]. As such, it has been suggested that the QSA is best conducted at the height of (or close to) the time of the primary analysis [40]. In general, while the debates on time as a factor influencing the effectiveness of QSA remain underdeveloped, it a particularly important area for future consideration [26].

In light of these debates, while taking a culturally sensitive position, we advocate (and examine in this work) the position of the same (primary) researchers conducting the secondary analysis and maintaining a high level of proximity to the original research. This is to both leverage the cultural knowledge accumulated in primary analysis and to maintain the privacy to our participants. We emphasize the need for such a cautious approach particularly when working with culturally specific groups from underrepresented populations. Thus, the researchers and the focus of the secondary analysis, should remain rather close to the primary focus to ensure the related contextual knowledge is fully accounted for [56].

In this work, the secondary analysis was conducted by the same primary researchers, close to (the same year) of conducting the primary analysis, and with a purpose derived from the existing data. In doing so, we undertook a bottom-up approach to understand culture as contextual concept.

\subsection{A Step-By-Step Protocol For Conducting QSA in Cross-Cultural Design}

Drawing on the discussion above, and reflecting upon our own experience we provide a set of practical steps below. Note that Step 4 is an overarching consideration that shades into the overall design of the study.

3.3.1 Step 1: Select A Qualitative Hci Dataset That Has A Strong Cultural Focus. An important initial step is the identification of appropriate datasets to conduct QSA. Some datasets are more suitable for cultural analysis than others: in particular, we would argue that there should be an inherent 'cultural focus' in the design of the original (chosen) studies to make them appropriate as source material. A cultural focus could arise from either the core part of the study (i.e., be one or more of the research questions) or alternatively the nature of the population. The focus of the primary study that is chosen for QSA should be investigating the informants' experiences within their wider cultural group and the mutual influence between the individual and the group. What's more, if the population's culture is being referred to constantly in the data, even if that was not the core focus of the original research, such a dataset may still have the potential to reveal rich cultural insights and thus allow generating cultural dimensions. In terms of the number of datasets, while one dataset may be sufficient, working with under-studied populations may urge the use of more than one dataset to cross validify and ensure we identify more relevant cultural dimensions while accounting for the inner diversity within the group.

We demonstrate this step in our two case studies in which the primary research questions had a strong cultural focus: the first investigated the cultural conceptualization of women' visibility and the second investigated digital privacy identity presentation to 
one's cultural milieu (section 4.2 and 4.3). We also demonstrate the nature of our transnational population and how the 'acculturation' process is a core part of their identity, thus our participants made a constant reference to their home culture and the host country's culture (section 2.5).

3.3.2 Step 2: Construct A New Focus (Research Question) That Aims At Generating Cultural Dimensions. Ultimately, QSA involves analyzing research data with a new set of research questions. While we advocate QSA to be conducted by the primary researchers (for reasons discussed in section (3.2.1), it is important that upon returning to the data one considers it afresh, in line with the new purpose of the QSA study. This can be facilitated by constructing a new focus better articulated as a 'what' question since the goal is identifying cultural dimensions regardless of 'how' they are affecting the informants' responses. For example, a question could be articulated as: What are the shared cultural aspects referenced by the informants as influential factors in their daily life? (instead of: 'how' is the informants' culture influencing their views?) Defining the 'how' aspect is instead a matter for consideration in Step 3, rather than being pre-ordained in advance.

We demonstrate this step in our secondary analysis in which we constructed a new research question as: "What cultural aspects of our participants' home country were influencing their attitudes and behavior?" (section 4.4).

3.3.3 Step 3: Re-Analyze Your Dataset By Identifying Highly Influential Factors: Both As Values And Obstacles. When the dataset has been selected and new research questions determined, one can progress to conduct the analysis. We emphasize the use of the term 'cultural dimensions' over 'cultural values' (as opposed to many top-down models) since we acknowledge that not all influential cultural factors are perceived as values by all participants. Indeed, some of these 'values' are instead perceived as obstacles by certain participants. Nonetheless, regardless of the 'how' - the kind of influence a given dimension is making, what makes a factor being a cultural dimension is the extent to which participants referenced its influence (either positive or negative). This should allow for each dimension to be inclusive of nuanced views represented in a spectrum as opposed to giving a fixed numerical score to each culture such as those in top-down models.

We demonstrate this step in our work by using Thematic Analysis (sections 4.4 and 6.2.2) and constructing three themes representing spectrums of values and barriers (section 5).

3.3.4 Step 4: Dealing with Potential Complexities. Throughout, there is a need to be mindful of the potential complexities that arise when studying culture. In our experience, the two main complexities arising from conducting QSA to generate cultural dimensions are: (i) the qualitative and subjective nature of this approach; and (ii) the labeling dimensions as a spectrum of views rather than a specific value.

The qualitative nature of this approach makes it difficult to easily decide on what makes a concept in the data a 'highly influential factor' and thus a dimension. Questions like "how many people mentioned a given concept" or "how much significance a concept was given by them" may seem hard to answer directly from the data. To address this, taking an off-the-shelf qualitative method, we found that reflexive Thematic Analysis [22] and the process of identifying themes aligns well with the process of identifying cultural dimensions following a bottom-up approach. (Further details are in section 6.2.2)

The other issue one may face in this process is articulating the cultural dimensions as value-free concepts. Unlike top-down models which assign specific values for each culture, we instead advocate assigning value-free dimensions that can represent the wider population rather than the dominant groups. To address this concern, we suggest presenting (and labeling) cultural dimensions within a clear spectrum, while containing the two extremes in its two ends (values and obstacles), to acknowledge the nuanced views of the population. (Further details in sections 5.3 and 6.1)

\section{STUDY DESIGN}

\subsection{Participants: Transnational Saudis in the US and the UK}

Our contribution derives from a joint secondary analysis [46] of data sets coming from two independent qualitative studies conducted with "transnational Saudis".

In total, our participants were 55 transnational Saudis ( 29 females, 26 males); that is, Saudi nationals who had experienced life in both Saudi Arabia and abroad (in our case, either in the US or the UK). They were abroad primarily for educational purposes and were undertaking a range of undergraduate and graduate courses. Participants varied in both their ages (18 to 40 years old), and in the time they had spent abroad (1 month to 11 years).

\subsection{Study 1: Focus Groups (Cultural Perceptions of Women's Visibility in Digital Media)}

The first author's research was a qualitative exploration of perceptions and attitudes of transnational Saudis towards the concept of women's visibility in digital media. The study aimed at engaging participants in the early stages of the design process to establish empathy with users, understand their cultural contexts and explore the space for designing technology that supports the visibility of women in the public sphere. To do this, semi- structured focus groups [27] were conducted to allow individuals express their thoughts the way they usually do among their peers in the same cultural context.

The study was conducted with three focus groups with 21 Transnational Saudis who were in the UK for educational purposes. The participants were recruited mainly through word of mouth and a Twitter advertisement. They ranged in age from 21 to 40, and education levels from bachelor's degree students (or holders) to $\mathrm{PhD}$ students. We conducted a mixed gender focus group (5 Females and 3 Males) to reflect the shared understanding between men and women. Then the following workshops were gender specific, (one with 5 females and the other with 8 males). Each session lasted for approximately two hours and were conducted in Arabic and English. 


\subsection{Study 2: Interviews (Transnational Saudis: Privacy and Identity in Social Media)}

The second author's research was a qualitative exploration of transnational Saudi's experience of social media and their understandings and practices in relation to privacy and identity. The study aimed at examining the participants' use of social media and how they experience privacy coming from a Muslim population and going through their transnational journey across two cultural contexts vis-à-vis social media. To gain an in-depth understanding of the participants' use of social media, ethnographically informed semi-structured interviews were employed [60]. During the interviews, participants were asked about their general use of social media, any incidents that led to private information being exposed, moments of surprise, as well as any negative and positive experiences.

The interviews were conducted with 34 participants $(M=15$, $\mathrm{F}=19$ ), ranging in age being 18 and 35 . The interviews lasted for 1.5 hours each and were conducted in Arabic and English. The cross-sectional aspect of this study required us to recruit balanced gender samples in two field sites, Saudi Arabia and in the USA using snowballing and purposeful sampling techniques.

\subsection{Unified Secondary Analysis}

In qualitative research, conducting a re-analysis across two or more studies can reveal mutual observations and review each study in relation to the other in order to draw a wider conclusion about certain phenomena or communities [83]. This is particularly valuable for studies with under-researched populations and sensitive topics, where access to more information may be difficult or impractical [35]. In our secondary analysis with an under-researched population, the commonalities between the two studies revealed a set of recurring cultural traits underpinning much of our participants' perceptions, which we synthesized and refer to as cultural dimensions.

The unified goal in this secondary analysis is to define what cultural aspects of our participants' home country were influencing their attitudes and behavior. Before the unified analysis, all sessions of both studies had been audio recorded, transcribed and analyzed thematically [21] for their original (primary) purposes. For the unified (secondary) analysis, each study was re-analyzed separately with the unified focus of identifying shared influential cultural aspects. The common high-level themes were identified to guide a collaborative iterative process. These generated more specific themes and subthemes which were synthesized and categorized into the final themes, which in turn were formulated as cultural dimensions and stakeholders (in the findings section). The commonalities between the two studies were readily apparent, that is, the overarching themes of significant traits shared among our participants' transnational identity guided our further analysis. Moreover, the differences in the configuration of the two studies lends significant weight to the validity of our unified findings. In particular, the different participants and methods (focus groups and interviews), furnished us with three distinctive qualitative data collection scenarios: a mixed-gender focus group, two gender-specific focus groups, and (34) in-depth interviews.

\section{FINDINGS}

Our participants' accounts of their perceptions and attitudes revealed a juggling process between the cultural dimensions we came to characterize into 3 categories. These are not easily separated from one another and have many interconnections, but we discuss them separately for clarification purposes. Each dimension may influence individuals' attitudes and behavior in different directions and/or intensities. Thus, each dimension is best represented on a spectrum to reflect the diversity among participants and indeed the diversity within one's own attitudes in different situations.

\subsection{Religious Adherence: A Value $\leftarrow \rightarrow$ An Obstacle}

Coming from a historically conservative and religious culture, most of our participants indicated the influence of their religion (Islam) on shaping many aspects of their identity. In some cases, they expressed the societal expectations and pressure on them to exhibit religious attitudes. Either way, this demonstrated that religion is a very relevant cultural dimension that they consider in their daily lives whether held as a value or perceived as a duty.

An explicit example of religion being an essential factor in our participants lives was evident in [AF-F4]'s comment below when she was discussing "being a Quran memorizer" as a high achievement.

"I feel that no matter how much I do in science, I would never reach their [Quran memorizer'] level ... [even if] they only completed college and some of them are still jobless, but I would still wish to be like them"

Despite being an academic, a PhD student in a STEM area and a mother, [AF-F4] expressed how she feels less of an achiever compared to those she referred to as "Quran memorizers". Meanwhile, other participants in the session seemed to take this as an accepted ideal. Even in cases where our participants did not provide such an explicit statement, the basis on which they justified their attitude and behavior in most cases had a religious reference. For instance, [PF16] stated that despite enjoying sharing photos online, she is afraid of accumulating sins from every user watching her photos, and thus she chose to put religion first before other choices:

"Recently, I deleted most of my photos from Instagram. Mostly because I was afraid of God. I am exposing so much of myself, my face and parts of my body to men that are not related to me and I started thinking what If I died and these photos stayed!"

Interestingly, considering (and prioritizing) religious choices does not only stem from "fear of God" as in [PF16]'s comment, but also religious choices are believed to create a better society, even if one does not prefer to adopt a religious choice. This attitude can be exemplified in [AB-M1]'s comment who considers religious prioritizing one's choices over religious moralities as a selfish act:

"if I consider what she [a Saudi female model] is doing as an achievement, it's like I'm cultivating a bad culture for the country, and this is a responsibility. So, in my opinion, I don't see what she's doing as a pride for the country, it's the opposite" 
From this excerpt we can see that [AB-M1]'s sense of responsibility to maintain a moral society makes him conscious about his choices (e.g. choosing how to judge certain acts). As such, religion seems to have a stronger influence on day-to-day behavior, sometimes being over and above one's own choices. This notion of the role religion plays in our participants' attitude was explicitly stated in this following excerpt when participants were asked about the criteria for evaluating women's achievements:

[AB-F3]: "my criteria are my society's and religion's criteria"

[AB-F2]: "religion is the most important thing".

It is noticeable that at times, our participants' accounts of 'society', 'culture' and 'religion' seem to be treated as if they are one and the same, as opposed being separate constructs. This is perhaps understandable given the fact religion and culture in their home country are deeply intertwined. For instance, [PF3], attributed her privacy practices to Islamic views and traditions, yet she associated these views with the country as a whole and the "small town" she came from. To some extent, she was distancing herself from these views:

"It is mostly Islamic views and traditions here in Saudi Arabia and my town... Especially that I am from [a small town], for girls it is not common to post our pictures".

Similarly, in [AB-F2]'s comment below when asked to evaluate women's achievements she stated:

"now we reached a point where I separate myself from my culture and religion and then evaluate her [a Saudi model], if I evaluate her like that, being separate and neutral, I'd say she has achieved something, but I can't".

It is interesting to observe that some participants actively distinguish between the different judgements they would have made have they distanced themselves from their home culture and religion. We categorize this attitude as itself being a cultural dimension, which takes the form of a spectrum of collectivist/individualistic attitudes (in line with Hofstede's [33] and others).

\subsection{Cultural Conformity: Autonomous $\leftarrow \rightarrow$ Collectivist}

Coming from a highly collectivist culture [43], our participants expressed the struggle between enacting their autonomous self and collective self [2], that is, between behaving in an individualistic or collectivist manner. This struggle is not simply between their desires and what others impose on them rather, at times, it is coming from the same individual where they enact either facet of themselves depending on what they perceive as morally imperative.

The main struggle our participants expressed was to act in an individualistic manner. This struggle positively correlates with the proximity and presence of others from the same culture. Our transnational participants though expressed some cultural changes they adopted, admitted the struggle to exhibit such changes in front of their families and social milieus. For instance, [PM9] explicitly stated the need to hide his other 'side' referring to his autonomous self, from his family:
"I have a special [social media] account that excludes my family. It is only for my US audience, ... I take photos of everything and I share them. I'm not conservative at all but I have a conservative family. I don't want them to see this side of me".

Although the notion of creating multiple accounts for multiple audiences seems to provide a strategic solution, however, some found this inherently stressful and difficult to manage. For instance, [PF4], described it as being a form of 'paranoia':

"I deleted a lot of people when I went [abroad] because I don't like this sense of paranoia. .. I don't like to create lists or multiple accounts"

By people, [PF4] was referring to those from her home country. Although this phenomenon seems applicable to both female and males, our impression from the data is that it is accentuated with females. At one case, a female participant [AF-F3] explicitly stated:

"I don't feel comfortable around Saudi guys".

In this quote she was referring to the fact she cannot be herself when interacting with male colleagues abroad who are coming from her country. This is because exhibiting her individual attitude that she gained in her transnational experience does not conform to her home culture norms. These norms expect women to be more private rather than openly expressing themselves, as explained by [PF8]:

"in Saudi, privacy is forced on you. You have to be private ... it is society telling you as a woman to be private. . .because of religion and culture".

Therefore, women in particular, have an ongoing concern for protecting their personal reputation, social status, and that of their families. As such cultural conformity is key for this protection. However, such conformity proves difficult given the fact almost everything a woman does will be scrutinized and criticized as stated by [AF-F1]:

"the society would always have some people who are actually against the whole idea of you going to study abroad, so you can't really satisfy everyone".

On the other hand, our participants expressed some levels of collectivism. Namely, having a strong sense of social ties with other societal groups, our participants constantly referred to the importance of their families and home society as their primary source of support and belonging. For instance, [AF-F4] expressed how she prioritized her family's opinions in any action she would do above anyone else's including hers:

"what matters to me is who are those who are not accepting what I want to do? If they were my family, I would not proceed ... otherwise if my family [is] proud of it, honestly I don't care about the rest of the society".

Similarly, [PF2] expressed her conception of 'what's right and what's wrong' as something mainly derived from what her family 'permits'

"Families clarify this from childhood. We are raised with an understanding of what's right and what's wrong. It might not be explicitly about not posting 
pictures, but with growing up with what is permitted and what is not"

The same applies even in cases where one is not a cultural conformist, some participants expressed they would conform by choice just to show respect. This was explicitly stated by [PF11]:

"Whenever I am taking photos for the public, I am wearing [a] hijab. . .because I want to pay respect to my cultural traditions".

From the perspective of cultural conformity, it is evident that our participants are not completely "collectivists" as some popular models of cultures would classify them, this is perhaps (or not) due to their transnational experience. However, they still struggle to exhibit individualistic attitudes for the reasons presented above. Thus, conformity seems to be the dominant norm in Saudi culture even among transnational individuals. The emphasis on cultural conformity seems to influence and perhaps is influenced by political conformity, as we demonstrate next.

\subsection{Political Allegiance: Fear $\longleftrightarrow \longrightarrow$ Revere}

Because the Saudi legal system is based on Islamic Sharia Law, the State and religion are broadly inseparable. Hence, this has contributed greatly to our participants' sense of duty towards the State (i.e. the government). This is perhaps countering the mainstream narrative of "fear" being the driving force for citizens abiding by the laws in Saudi Arabia. However, we learned from our participants that the two narratives co-exist both even within one individual as we described earlier, where different situations invite enacting different facets of the self. As per the mainstream narrative, there does exist a sense of fear from authority which forces people to selfcensor their behaviors be it online, at home or abroad, as expressed by [PF6]:

"the reason why my Facebook Wall is kept to my friends only is because I don't have trust in the government ... I have to always censor my opinion on stuff".

In her statement, [PF6] was referring to the risks of freely expressing her political views. Interestingly, even in cases where one expresses or shares non-political views, they could still face political repercussions if they do not exhibit cultural conformity. An example of this is going to a night club, as stated in [PM8]'s comment:

"if you post about being at a club you could risk your opportunity to get a job in Saudi. One of my friends told me that I am not very careful. I have another friend that also lost a job offer because of a political post. After that, I went to my account and I deleted two posts from my Facebook that involved Saudi political figures ... social media in general, is heavily monitored in Saudi”.

Thus, avoiding political discussions, even while living abroad, is still the norm our participants as they are aware of the internet being censored by an extremely centralized infrastructure. On the other hand, the data also revealed a co-existing narrative stemming from both reverence to the State as a power enacting Islamic law. This is exemplified in [AB-F2] comment about a female activist who drove her car in 2012 (before the lifting of the ban in 2018):
“The place where you do your 'achievements', you should follow its rules. It would be a jungle otherwise. As Muslims, we'll always belong to the place where we are from, we express our identity with our morals no matter how much we don't like these rules ... There is a way to changing the laws within the rules ... like through the Shura ${ }^{1}$ Council"

Here, [AB-F2] not only justified her view from a religious perspective, but also touched upon another perspective: national safety. In her using the metaphor of the "jungle", she referred to "anarchy" as a dangerous state which was perhaps witnessed in other neighboring countries and thus resulted in fear of losing national safety. Similarly, [PF9] echoed this by expressing that despite her support for making cultural changes, she does not support pushing for them by force:

"I'm against the Women2Drive campaign. I don't support the way the movement was established and tried to push change by force, but I am supportive of the goal".

Indeed, national safety is a critical factor influencing most of our participants political orientations regardless where they fall on the conservatism/liberal spectrum. Maintaining this safety does not only represent an internal issue with either extremists or activists, but also with the media (particularly Western) and how it casts the mainstream narrative of the country and its citizens. This seems to influence our participants' online behavior and their awareness of which narrative that their posts may cast. For instance, [PM5] stated that he intentionally:

"do[es] not share any negative news about Saudi on Facebook. I only share good news”.

The underlying intent of such behavior is to protect the state's reputation as described by [AM-M8] who condemned an activist for "tarnishing" to the image of the State:

"in the West she has tarnished the reputation of Saudi Arabia”.

The other reason is that the mainstream narrative, which is supported by activists, may not represent the overall population as stated by [AF-F4] in her comment about another activist:

"she talked on our behalf and used 'we' when she should've said 'I' and talked about herself. Those who do not like it here should just leave for another nation, go abroad and live the free life that you wish. But do not represent Saudi Arabia and say I am a Saudi and I ask for these rights".

The problem of representation was also attributed to "the West". For instance, maintaining a positive image of the state was expressed as a strategy to break the stereotypical narrative portrayed by "the West", as [AF-F3] commented on a female athlete (who does not wear an Islamic attire):

"For me, [she is an achiever] because she reflects an image for those [the West]. [they see us as] the negative others, the weird others, the others, they always ... in everything and every topic they would refer

${ }^{1}$ The Consultative Assembly of Saudi Arabia: the formal advisory body for the State. 
back to women ... 'she doesn't drive!' This is their cliché (stereotype), and that she can't go anywhere without a male guardian."

What is surprising in this comment in particular is that [AF-F3] was supportive of the aforementioned athlete despite not being culturally or religiously conformist, yet reflecting a "positive image" of the State. This means perhaps at times, protecting the national reputation can be of a higher value than conforming to one's own faith or culture if these come in a conflict. The State thus seems to be not only feared for its intolerance of counter-discourse, but also highly respected for being intertwined with religion and for protecting national security.

Overall, it appears to be a problem of representation where our participants feel less represented by the mainstream media, activists, and even by their own social media accounts. This has created an identity struggle manifested in their duality between their individualistic transnational and collectivist national identity.

\section{DISCUSSION}

\subsection{Understanding Culture in Cross-Cultural Design}

Unlike the deterministic nature of typical top-down cultural models with a set of pre-defined universal dimensions, the use of QSA allowed us to distil cultural dimensions from the ground up using existing data obtained from a culturally specific group. Such an approach yielded a deeper and context specific conceptualization of culture and cultural dimensions as demonstrated in the findings (and this discussion).

By doing so, we do not claim that such an approach should replace universal cultural models, rather it is meant to provide a closer lens to examine the specificity of each culture. For instance, Hofstede's dimensions are universal with numerical classes. In contrast, in a bottom-up approach, we can go beyond a universal dimension and instead investigate the cultural specificity in a given context. For example, in regard to the "collectivism" dimension in Hofstede's model, each culture is given a score (out of 100) which makes it either a collectivist or individualist culture. By contrast following a bottom-up approach can provide a deeper meaning on how that dimension "i.e., collectivism" is constructed uniquely in a given culture. An example from our data is "Religious Adherence" which represents an influential facet of the nature of collectivism and how it plays out in the culture of this specific population. By doing so, we respond to Sun's [70] and Amant's [69] calls for cross-cultural designers to develop richer and deeper knowledge of cultural contexts beyond the universal cultural models.

Since QSA is grounded on real accounts of many individuals, QSA allowed us to reveal distinctive aspects of culture that may not have been captured through universal cultural models. As such we address an often criticized limitation with these models, which is that they overlook cultural specificities. By doing so we respond to the calls for approaches to culture as a subjective construct in which individuals have cultural agency and do not merely serve as "dopes" of culture [75].
For instance, the dimensions of top-down models (e.g. collectivism and masculinity) are pre-defined, constructed by scholars rather than being constructed from the ground up based on real accounts. As such, they are used universally to measure and compare cultures rather than exploring the distinctive aspects of each culture. By contrast, a bottom-up approach allows revealing culturally specific dimensions that cannot be pre-defined, and thus are not necessarily applicable to other cultures. Therefore, they cannot be claimed to have utility for universal cultural comparisons. One example from our analysis is "fear or reverence to the State" which reveals a culturally specific factor influencing people's everyday lives, be it due to fear and lack of trust in the state as per [PF6], or a value and a religious practice as per [AB-F2].

In line with subjective approaches to culture [48, 75], we offer the use of QSA as a bottom up approach leveraging rich qualitative data through the use of secondary analysis to learn about the cultural context of our participants. We emphasize this approach builds on and complements rather than replaces existing models. Thus, we hope to move this debate further by considering both objective and subjective approaches to culture while minimizing the limitations of each approach. The critical distinction is that while objective approaches are deterministic and designed for cross-cultural comparison, a subjective approach can facilitate a richer and more context specific understanding of culture.

Moreover, following QSA revealed the co-existence of different narratives alongside those deemed as stereotypical. For instance, contrary to the mainstream narrative of fear being the driving force for political allegiance, some participants expressed high reverence to the State as both a power enacting their faith and protecting national safety. While some participants expressed their indifference or even mistrust in the State, nonetheless, fear of potential repercussions is constantly present in their daily life. This co-existence of different narratives while revolving around one concept revealed the critical role that concept plays in a culture yet allowing to shed light on existing nuances.

As illustrated with our participants, different strategies have been adopted by those who do not conform to existing societal norms, yet they still identified how these cultural dimensions played a significant role in how they express their non-conformity. While some of these expressed indifference in taking these dimensions in considerations just to "pay respect" to their culture as in [PF11], others played a dual role of being simultaneously conformist and non-conformist by, for example, creating different social media accounts for different audiences as in [PM9]' case. Nonetheless, these are different strategies yet influenced by the same cultural dimension and concerns (religious adherence / cultural conformity).

Therefore, using this approach addresses some critiques that associate the concept of culture with imposing homogeneity, rigidness, superiority [17, 23, 42], stereotyping [19] and cultural essentialism [33]. Such fallouts of using 'culture' may be the result of adopting more deterministic approaches to culture. However, in a flexible and bottom-up approach the effect of such (mis)usages of culture can be minimized.

We identified three overarching cultural dimensions which represent the main influential aspects underpinning much of our participants' views and values. Whilst we labelled them as: (i) Religious Adherence, (ii) Cultural Conformity and (iii) Political Allegiance, we 
Table 1: The key distinctions between QSA and predominant cultural models

\begin{tabular}{|c|c|c|c|}
\hline & Cultural models & QSA & Added value \\
\hline Approach & Top-down & Bottom-up & $\begin{array}{l}\text { Although top-down approaches use pre-defined universal dimensions } \\
\text { that allow for cross-cultural comparison, a bottom-up approach allows } \\
\text { for dimensions to be constructed from the ground up to reveal more } \\
\text { culturally specific dimensions }\end{array}$ \\
\hline Methodology & Quantitative & Qualitative & $\begin{array}{l}\text { Whilst quantitative approaches adopted in top-down models allow for } \\
\text { measuring cultures by giving them specific scores against each } \\
\text { dimension, qualitative approaches allow for identifying a wider range } \\
\text { of views represented in each dimension. }\end{array}$ \\
\hline $\begin{array}{l}\text { Nature of } \\
\text { dimensions }\end{array}$ & $\begin{array}{l}\text { Value-laden } \\
\text { numerical } \\
\text { dimensions }\end{array}$ & $\begin{array}{l}\text { Spectrums of } \\
\text { nuanced dimensions } \\
\text { of values and } \\
\text { obstacle }\end{array}$ & $\begin{array}{l}\text { While cultural dimensions in top-down models represent cultural } \\
\text { values in the form of a value-laden concept (e.g. culture } \mathrm{x} \text { is collectivist), } \\
\text { bottom up approaches allow for constructing dimensions representing } \\
\text { the nuances of views whether values or obstacle or in between. (e.g. } \\
\text { factor X is influential in culture Y as a value, an obstacle or both) }\end{array}$ \\
\hline
\end{tabular}

present them as being spectrums reflecting the nuances amongst individuals. Importantly, the use of QSA allowed us to easily identify the different narratives that co-exist under each dimension. These dimensions represent spectrums of culturally influential concepts which vary in how they influence each individual.

As such, we do not refer to these as cultural values per se, rather, influential dimensions which could represent values or barriers which addresses the critiques cultural models have received regarding the static view of culture and the reinforcement of stereotypes. That is to say, this approach allows different (and contradictory) narratives to co-exist to reveal the nuances and diversity within our participants' views. Unlike with top-down models, this approach acknowledges the influence of culture on individuals regardless of their orientations towards existing cultural norms (i.e., whether or not individuals actually conform to cultural norms).

1 provides a summary of the key differences between using QSA and typical cultural models (Hofstede's as an example) and how QSA as a bottom-up approach adds value to top-down models.

\subsection{Implications for Cross-Cultural Design (And HCI)}

6.2.1 The Choice Of Primary Dataset. The most appropriate choice of primary dataset is not always easy to determine. Qualitative datasets are rich and 'messy', and it is not easy to judge their suitability for constructing cultural dimensions without having been immersed in them. In our experience, even after that immersion and finalizing the primary work, it was still necessary to look back at the data with fresh eyes looking for mentions and clues pertaining to cultural concepts, such as cultural entities (e.g., family, religious police), cultural values (e.g., conformity or harmony), and cultural barriers (exclusion or impositions). While typical qualitative datasets may include references to cultural concepts, the extent of this depends heavily on the nature of the primary research question and the topic discussed with participants. For instance, the nature of the two studies in this work had a strong cultural focus: the first study looked at the culturally shared conceptualization of women's visibility and the second looked at digital privacy and how one presents (or not) their identity to their cultural milieu (in comparison to those outside their milieu). Therefore, the nature of the conversations we had with our participants included a constant reference to their social circles, cultural norms and cultural behavior. Moreover, the nature of this population (i.e. transnational) triggered constant comparisons to their dual lives both to their home culture and the new culture to which they immigrated. Consequently, not all qualitative datasets would be suitable for this endeavor, nor can we claim that certain topics or certain studies are better suited. Rather, as we learned from our analysis, culturally oriented studies may (or may not) offer such an opportunity depending on the nature of the conversation that took place with the research informants. It is thus the primary researcher's responsibility to make the judgement of whether or not a given dataset is suitable for a QSA aimed at generating a 'bottom up' account of culture.

6.2.2 The Choice Of Conceptualizing Dimensions. Whilst the analysis of culturally oriented studies may offer many different culturally specific concepts, taking a decision on which of these concepts actually comprises a cultural dimension can be a puzzling endeavor. Unlike Hofstede's model and other cultural models where the dimensions are predefined, the use of QSA to construct dimensions is derived from data. In our experience, one possible way to achieve this goal is through the use of Thematic Analysis (TA) [22]. This is because the goal of a bottom-up approach to culture is to identify the most influential cultural concepts (themes) from the data. In alignment with TA, we do not claim that cultural dimensions are emergent from the data, rather, we acknowledge the researchers' conscious construction of these dimensions. With this emphasis on the researcher's active role in constructing cultural dimensions, it becomes imperative that the researcher should have an established understanding of the cultural context. For this reason we argue that QSA is best conducted by the same primary researchers $[26,40,47,56]$ who have been already immersed in the data and are already familiar with the cultural context. In our case, both researchers are the primary researchers of the two datasets, and both identify as transnational Saudis, thus making them more familiar with the participants cultural contexts. As a result, not all qualitative researchers may find constructing cultural dimensions 
to be a natural process. Rather, the more immersed the researchers and the closer they are to the cultural context, the more natural it would be to achieve such a goal.

6.2.3 The Choice Of Operationalizing Dimensions. Similar to the popular cultural dimensions in, for example, Hofstede's widelyapplied model [33], the dimensions generated from QSA are abstract concepts that are not readily applicable in design work. While the traditional cultural dimensions have been applied in design work mostly for comparison (e.g. [4]) evaluation (e.g. [50]), and guiding analysis (e.g. [81]), bottom up cultural models are better suited for earlier stages of the design process (i.e. before conducting comparisons, evaluation or analysis) although they could be used loosely in these stages. The point of these cultural dimensions is to provide a richer and deeper understanding of the cultural context early in the design cycle which could guide consequent stages. As such, these dimensions are meant to help researchers to ask better and more relevant questions to the study population and to explore more relevant problems in the design space. We thus propose the use of QSA to deepen our understanding of culture to hopefully guide designers and enhance their cultural sensitivity in cross-cultural design. Consequently, the dimensions resulting from QSA can inform the selection (or design) of methods, tools, and strategies when engaging in culturally sensitive user research. By understanding the relevant dimensions identified, researchers can utilize these to guide the design of their empirical work and communication with participants. In our experience, this understanding has helped better communicate and "speak the user's language", ask relevant questions and examine the effect of relevant cultural values in subsequent studies.

\subsection{Limitations and Future Work}

Unlike universal cultural models applied on wider scales of cultures (i.e. nations), our use of QSA is perhaps limited to smaller scales of culture (e.g. subgroups of certain nations). This means that we cannot necessarily claim the use of QSA can be appliable for wider scales and more diverse groups, albeit this approach might be promising in that regard. We invite design researchers to explore the use of QSA on different groups with larger (or smaller) scales to enrich the conversation on utilizing QSA in design work. Similarly, whilst we do not consider this approach to have provided an exhaustive understanding of culture (nor we do we believe there is an single approach that could understand culture to an 'exhaustive standard' by itself), our use of QSA serves as a complementary approach to enrich the outcomes of the universal models by guiding the process of design research rather than evaluating design or directly applying cultural dimensions in design. Finally, we observe that we positioned this type of investigation at the early stages of user research (before any design concepts were investigated): as such we hope to evaluate its success in guiding subsequent stages of the design process (e.g. conducting a culturally sensitive empirical investigation) in future work, so we can build upon and refine this approach going forward.

Finally, while we cannot claim our findings are unique to the use of QSA, what we claim here is that our findings present more culturally specific dimensions as opposed to the universal dimensions (e.g., Hofstede's dimensions). As such, our goal (and call for researchers) is to explore bottom-up approaches to address the limitations of universal models, whether these are off-the-shelf such as QSA or newly developed methods.

\section{CONCLUSION}

Obtaining an accurate understanding of culture can be difficult, especially in marginalized populations, where subtle misunderstandings and assumptions can influence the result of qualitative investigations. In response to both the limitations of universal cultural models employed in Cross-Cultural Design and calls for a more subjective and context specific conceptualization of culture, we proposed the use of QSA as a method to transcend these existing limitations. Drawing on two qualitative studies with 55 participants, we demonstrated how QSA facilitated establishing a cultural understanding from the ground up. The distinctive characteristics of this approach, compared to universal models, were identified including providing a more dynamic and nuanced view of culture. More broadly, we raise awareness of the possibilities (and pitfalls) of QSA from both epistemological and practical grounds. We found that QSA is not only a method of generating rich and contextual insights especially with underrepresented or elusive groups, but also it offers pragmatic possibilities of exploring the hidden knowledge and underutilized data in a wide range of qualitative $\mathrm{HCI}$ work.

\section{ACKNOWLEDGMENTS}

This work was in part completed at Newcastle University, UK, funded by the Saudi Cultural Mission.

\section{REFERENCES}

[1] Norah Abokhodair, Sofiane Abbar, Sarah Vieweg, and Yelena Mejova. 2016. Privacy and twitter in qatar: Traditional Values in the Digital World. Proceedings of the 8th ACM Conference on Web Science - WebSci '16 (2016), 66-77. DOI: https://doi.org/10.1145/2908131.2908146

[2] Norah Abokhodair, Adam Hodges, and Sarah Vieweg. 2017. Photo Sharing in the Arab Gulf: Expressing the Collective and Autonomous Selves. In Proceedings of CSCW 2017, ACM Press, 696-711. DOI: https://doi.org/10.1145/2998181.2998338

[3] Norah Abokhodair and Sarah Vieweg. 2016. Privacy \& Social Media in the Context of the Arab Gulf. DIS '16 Proceedings of the 2016 ACM Conference on Designing Interactive Systems (2016), 672-683. DOI: https://doi.org/10.1145/2901790.2901873

[4] Zakari Abubakari, Min Wang, and Rexford Paa-Grant. 2018. Hofstede-GLOBE inspired cultural dimensions: a review and application in international business research and cross-cultural strategy. In Proceedings of the 2018 International Conference on Information Management \& Management Science - IMMS '18, ACM Press, Chengdu, China, 83-88. DOI: https://doi.org/10.1145/3277139.3277153

[5] Nitin Agarwal, Merlyna Lim, and Rolf Wigand. 2012. Raising and rising voices in social media: A novel methodological approach in studying cyber-collective movements. Business and Information Systems Engineering 4, 3 (2012), 113-126. DOI: https://doi.org/10.1007/s12599-012-0210-z

[6] Manail Anis Ahmed. 2015. Outward Mobility of Saudi Students: An Overview. International Higher Education 83 (December 2015), 19. DOI: https://doi.org/10. 6017/ihe.2015.83.9084

[7] Jamil Al Wekhian. 2015. Acculturation Process of Arab-Muslim Immigrants in the United States. Asian Culture and History 8, 1 (November 2015), 89. DOI: https://doi.org/10.5539/ach.v8n1p89

[8] Adel Al-Dawood, Norah Abokhodair, Houda El mimouni, and Svetlana Yarosh. 2017. "Against Marrying a Stranger": Marital Matchmaking Technologies in Saudi Arabia. In Proceedings of the 2017 Conference on Designing Interactive Systems DIS '17, ACM Press, Edinburgh, United Kingdom, 1013-1024. DOI: https://doi. org $/ 10.1145 / 3064663.3064683$

[9] Majid Aldraehim, Sylvia L Sl Edwards, Jason Watson, and Chan Taizan. 2013. Cultural impact on e-service use in Saudi Arabia: the need for interaction with other humans. International fournal for Infonomics (IfI) 3, 3 (2013), 655-662.

[10] Madawi Al-Rasheed. 2013. A Most Masculine State: Gender, Politics, and Religion in Saudi Arabia. Cambridge University Press. 
[11] Mohammed Alsaif. 2014. Factors Affecting Citizens' Adoption of e- Government Moderated by Socio and Cultural Values in Saudi Arabia. Ph.D. Dissertation. University of Birmingham, Birmingham, UK, Birmingham, UK.

[12] Taghreed Alshehri, Reuben Kirkham, and Patrick Olivier. 2020. Scenario CoCreation Cards: A Culturally Sensitive Tool for Eliciting Values. CHI 2020 (2020), 14

[13] Abdullah Mohammed AL-Shehry. 2008. Transformation towards E-government in The Kingdom of Saudi Arabia: Technological and Organisational Perspectives. Ph.D. Dissertation. De Montfort University, Leicester, UK

[14] Tamara Alsheikh, Jennifer a. Rode, and Siân E Lindley. 2011. (Whose) ValueSensitive Design? A study of long- distance relationships in an Arabic cultural context. Proceedings of the ACM 2011 Conference on Computer Supported Cooperative Work (CSCW'11) (2011), 75-84. DOI: https://doi.org/10.1145/1958824.1958836

[15] Kirk St Amant. 2015. Introduction to the special issue Cultural Considerations for Communication Design: Integrating Ideas of Culture, Communication, and Context into User Experience Design. (2015), 17.

[16] Andrew Molinsky. 2007. Cross-Cultural Code-Switching: The Psychological Challenges of Adapting Behavior in Foreign Cultural Interactions. The Academy of Management Review 32, 2 (2007), 622-640.

[17] John W. Berry, Ype H. Poortinga, Marshall H. Segall, and Pierre R. Dasen. 2002 Cross-Cultural Psychology: Research and Applications. Cambridge University Press (2002), 611.

[18] Dinesh Bhugra and Matthew A. Becker. 2005. Migration, cultural bereavement and cultural identity. World Psychiatry (2005), 7.

[19] Lawrence Blum. 2004. Stereotypes and Stereotyping: A Moral Analysis. Philosophical Papers 33, 3 (November 2004), 251-289. DOI: https://doi.org/10.1080/ 05568640409485143

[20] Mariya Bobina, Stephanie Vergnaud, Mikhail Grachev, and Richard Soparnot 2010. From cultural stereotypes to cross-cultural analysis: a case of France. In Proceedings of the 3rd international conference on Intercultural collaboration - ICIC '10, ACM Press, Copenhagen, Denmark, 3.

[21] Virginia Braun and Victoria Clarke. 2006. Using thematic analysis in psychology. Qualitative Research in Psychology 3, 2 (2006), 77-101. DOI: https://doi.org/The publisher's URL is: http://dx.doi.org/10.1191/1478088706qp063oa

[22] Virginia Braun and Victoria Clarke. 2019. Reflecting on reflexive thematic analysis Qualitative Research in Sport, Exercise and Health 11, 4 (August 2019), 589-597. DOI: https://doi.org/10.1080/2159676X.2019.1628806

[23] Christoph Brumann. 1999. Writing for Culture: Why a Successful Concept Should Not Be Discarded. Current Anthropology 40, S1 (February 1999), S1-S27. DOI https://doi.org/10.1086/200058

[24] Jean Pierre Cassarino. 2004. Theorising Return Migration: The ConceptualApproach to Return Migrants Revisited. International fournal on Multicultural Societies (IFMS) 6, 2 (2004), 253-279.

[25] Christopher Clary and Mara E. Karlin. 2011. Saudi Arabia's Reform Gamble. Survival 53, 5 (November 2011), 15-20. DOI: https://doi.org/10.1080/00396338. 2011.621619

[26] Carrie Coltart, Karen Henwood, and Fiona Shirani. 2013. Qualitative Secondary Analysis in Austere Times: Ethical, Professional and Methodological Considerations. Forum: Qualitative Social Research 14, 1 (2013), 20.

[27] John W. Creswell. 2014. Research design: qualitative, quantitative, and mixed methods approaches (4th ed ed.). SAGE Publications, Thousand Oaks.

[28] Janet Davis and Lisa P. Nathan. 2013. Value Sensitive Design: Applications, Adap tations, and Critiques. In Handbook of Ethics, Values, and Technological Design Jeroen van den Hoven, Pieter E. Vermaas and Ibo van de Poel (eds.). Springer Netherlands, Dordrecht, 1-26. DOI: https://doi.org/10.1007/978-94-007-6994-6_31

[29] Nicole Dubois and Jean Léon Beauvois. 2005. Normativeness and individualism. European fournal of Social Psychology 35, 1 (2005), 123-146. DOI: https://doi.org/ $10.1002 /$ ejsp.236

[30] Maha Faisal and Asmaa Alsumait. 2011. Social Network Privacy and Trust Con cerns. Proc. of the 13th International Conference on Information Integration and Web-based Applications and Services (2011), 416-419. DOI: https://doi.org/10.1145/ 2095536.2095620

[31] Batya Friedman, Peter H Kahn, and Alan Borning. 2002. Value Sensitive Design Theory and Methods. UW CSE Technical Report (2002), 8

[32] F. Gregory Gause. 2011. Saudi Arabia in the New Middle East.

[33] Geert Hofstede. 1981. Culture and Organizations. International Studies of Management \& Organization.

[34] Reece George, Keith Nesbitt, Michael Donovan, and John Maynard. 2012. Evaluating Indigenous Design Features Using Cultural Dimensions. User Interfaces 126, (2012), 10.

[35] Lisa M. Given. 2008. The SAGE Encyclopaedia of Qualitative Research Methods. SAGE Publications.

[36] Barney G Glaser. 1963. Retreading Research Materials: The Use of Secondary Analysis by the Independent Researcher. American Behavioral Scientist 6, (1963) 11-14.

[37] Edward T. Hall. 1976. Beyond Culture. Anchor Press, New York

38] Martyn Hammersley. 2010. Can We Re-Use Qualitative Data via Secondary Analysis? Notes on Some Terminological and Substantive Issues. Sociological Research
Online 15, 1 (February 2010), 47-53. DOI: https://doi.org/10.5153/sro.2076

[39] Shahad Hazmi and Sherif Mohamed. 2015. Influence of National Culture on Staff Preferences to Knowledge Sharing Practices: The Case of Saudi Arabia. In The 6th International Conference on Construction Engineering and Project Management, ICCEPM 2015, Busan, Korea, 7-11.

[40] Janet Heaton. 2004. Reworking Qualitative Data. SAGE Publications Ltd, 1 Oliver's Yard, 55 City Road, London England EC1Y 1SP United Kingdom. DOI: https: //doi.org/10.4135/9781849209878

[41] Pamela Hinds and Katharina Reinecke. 2014. Advancing methodologies for crosscultural studies of collaborative systems. In Proceedings of the companion publication of the 17th ACM conference on Computer supported cooperative work \& social computing - CSCW Companion '14, ACM Press, Baltimore, Maryland, USA, 323-326. DOI: https://doi.org/10.1145/2556420.2558856

[42] Mark Hobart. 2000. After culture: anthropology as radical metaphysical critique. Duta Wacana University Press, Yogyakarta.

[43] Geert Hofstede. What about Saudi Arabia? Retrieved August 26, 2019 from https://geert-hofstede.com/saudi-arabia.html

[44] Jeroen van den Hoven. 2015. Value Sensitive Design and Responsible Innovation. In Social Responsibility and Science in Innovation Economy, Pawelec Kawa and Rafael P Weirzchoslawski (eds.). Learned Society of KUL \& John Paul II Catholic University of Lublin, 115-164.

[45] Jeroen van den Hoven, Pieter E. Vermaas, and Ibo Van de Poel (Eds.). 2015. Handbook of Ethics, Values, and Technological Design Sources, Theory, Values and Application Domains. Springer Science+Business Media Dordrecht 2015, Delft, The Netherlands.

[46] Sarah Irwin. 2013. Qualitative secondary data analysis: Ethics, epistemology and context. Progress in Development Studies 13, 4 (October 2013), 295-306. DOI: https://doi.org/10.1177/1464993413490479

[47] Sarah Irwin and Mandy Winterton. 2011. Debates in Qualitative Secondary Analysis: Critical Reflections. Timescapes Working Paper Series 4 (2011), 24

[48] Michelle L. Kaarst-Brown and Indira R. Guzman. 2014. Cultural richness versus cultural large scale insights: culture, globalization, and it workers. In Proceedings of the 52nd ACM conference on Computers and people research - SIGSIM-CPR '14, ACM Press, Singapore, Singapore, 55-58. DOI: https://doi.org/10.1145/2599990. 2600002

[49] Sahar Khamis and Katherine Vaughn. 2011. Cyberactivism in the Egyptian Revolution: How Civic Engagement and Citizen Journalism Tilted the Balanc. Arab Media \& Society. Retrieved September 17, 2016 from http://www.arabmediasociety. com/?article $=769$

[50] Nouf Khashman and Andrew Large. 2012. Arabic web interface design through the eyes of Hofstede. Proceedings of the American Society for Information Science and Technology 49, 1 (2012), 1-3. DOI: https://doi.org/10.1002/meet.14504901369

[51] Nouf Khashman and Andrew Large. 2013. Arabic Website Design: User Evaluation from a Cultural Perspective. In Cross-Cultural Design. Cultural Differences in Everyday Life, P. L. Patrick Rau (ed.). Springer Berlin Heidelberg, Berlin, Heidelberg, 424-431. DOI: https://doi.org/10.1007/978-3-642-39137-8_47

[52] A. L. Kroeber and Clyde Kluckhohn. 1952. Culture: a critical review of concepts and definitions. Peabody Museum of American Archaeology and Ethnology, Cambridge, Mass.

[53] Amélie Le Renard. 2008. "Only for Women:" Women, the State, and Reform in Saudi Arabia. The Middle East Fournal 62, 4 (October 2008), 610-629. DOI: https://doi.org/10.3751/62.4.13

[54] Xin Li, Traci J. Hess, Anna L. McNab, and Yanjun Yu. 2009. Culture and acceptance of global web sites: a cross-country study of the effects of national cultural values on acceptance of a personal web portal. ACM SIGMIS Database 40, 4 (October 2009), 49. DOI: https://doi.org/10.1145/1644953.1644959

[55] Ping Liu and Chun Keung. 2013. Defining Cross-Culture Theoretical Framework of User Interface. In Cross-Cultural Design. Methods, Practice, and Case Studies, P. L. Patrick Rau (ed.). Springer Berlin Heidelberg, Berlin, Heidelberg, 235-242.

[56] Tracy Long-Sutehall, Magi Sque, and Julia Addington-Hall. 2010. Secondary analysis of qualitative data: a valuable method for exploring sensitive issues with an elusive population? Journal of Research in Nursing 16, 4 (July 2010), 335-344. DOI: https://doi.org/10.1177/1744987110381553

[57] Jerry D. Moore. 2009. Visions of culture: an introduction to anthropological theories and theorists (3rd ed ed.). AltaMira Press, Lanham, MD.

[58] Carlyle Murphy. 2012. A Kingdom's Future: Saudi Arabia through the eyes of its twentysomethimgs. Wilson International Center for Scholars, Washington, D.C. Retrieved from www.wilsoncenter.org/middleeast

[59] Caryle Murphy. 2012. Saudi Arabia's Youth and the Kingdom's Future. Middle East Program, Occasional Paper Series (2012). Retrieved from http://scholar.google.com/scholar?hl=en\&btnG=Search\&q=intitle: Saudi+Arabia's+Youth+and+the+Kingdom's+Future\#6

[60] W. Lawrence Neuman. 2014. Social Research Methods: Qualitative and Quantitative Approaches (7th ed. ed.). Pearson Education Limited, Edinburgh. Retrieved September 9, 2019 from http://www.jstor.org/stable/3211488?origin=crossref

[61] Khaled Saleh Al Omoush, Saad Ghaleb Yaseen, and Mohammad Atwah Alma'Aitah. 2012. The impact of Arab cultural values on online social networking: 
The case of Facebook. Computers in Human Behavior 28, 6 (2012), 2387-2399. DOI: https://doi.org/10.1016/j.chb.2012.07.010

[62] Daphna Oyserman. 2011. Culture as situated cognition: Cultural mindsets, cultural fluency, and meaning making. European Review of Social Psychology 22, 1 (March 2011), 164-214. DOI: https://doi.org/10.1080/10463283.2011.627187

[63] Daphna Oyserman and Spike W S Lee. 2008. Does culture influence what and how we think? Effects of priming individualism and collectivism. Psychological bulletin 134, 2 (2008), 311-42. DOI: https://doi.org/10.1037/0033-2909.134.2.311

[64] Tom Plocher, Pei-Luen Patrick Rau, and Yee-Yin Choong. 2012. Cross-Cultural Design. In Handbook of Human Factors and Ergonomics, Gavriel Salvendy (ed.) John Wiley \& Sons, Inc., Hoboken, NJ, USA, 162-191. DOI: https://doi.org/10. 1002/9781118131350.ch6

[65] Elisabeth Plum. 2009. Cultural intelligence: the art of leading cultural complexity. In Proceeding of the 2009 international workshop on Intercultural collaboration IWIC '09, ACM Press, Palo Alto, California, USA, 293. DOI: https://doi.org/10. $1145 / 1499224.1499280$

[66] Pablo Rodríguez Del Pozo and Joseph J Fins. 2008. Islam and Informed Consent Notes from Doha. Cambridge Quarterly of Healthcare Ethics 17, 3 (2008), 273-9. DOI: https://doi.org/10.1017/S096318010808033X

[67] Victoria Sherif. 2018. Evaluating Preexisting Qualitative Research Data for Secondary Analysis. Forum: Qualitative Social Research 19, 2 (2018), 17.

[68] Nitish Singh. 2002. From Cultural Models to Cultural Categories: A Framework for Cultural Analysis. In NA - Advances in Consumer Research, Association for Consumer Research, Valdosta, GA, 239-240.

[69] Kirk St. Amant. 2016. Introduction to the special issue: Cultural considerations for communication design. Communication Design Quarterly Review 4, 1 (2016), 6-22. DOI: https://doi.org/10.1145/2875501.2875502

[70] Huatong Sun. 2002. Why Cultural Contexts Are Missing: A Rhetorical Critique of Localization Practices. In Proceedings of STC (Society for Technical Communicators), Nashville, TN, 5.

[71] Huatong Sun. 2012. Cross-Cultural Technology Design Creating Culture-Sensitive Technology for Local Users. Oxford University Press. DOI: https://doi.org/10.1093/ acprof:oso/9780199744763.001.0001

[72] Huatong Sun. 2015. Operationalizing culture with design cards in cross- cultural design: Translating critical knowledge into provocative insights. Rhetoric Professional Communication and Globalization 7, 1 (2015), 61-78.

[73] Anna Tarrant. 2017. Getting out of the swamp? Methodological reflections on using qualitative secondary analysis to develop research design. International fournal of Social Research Methodology 20, 6 (November 2017), 599-611. DOI https://doi.org/10.1080/13645579.2016.1257678

[74] Fons Trompenaars and Charles Hampden-Turner. 2011. Riding the waves of culture: Understanding cultural diversity in business. Hachette, UK. Retrieved from https: //linkinghub.elsevier.com/retrieve/pii/002463019390118Y

[75] Sampo S.I. Tukiainen. 2010. Coping with cultural dominance in cross cultural interaction. In Proceedings of the 3rd international conference on Intercultural collaboration - ICIC '10, ACM Press, Copenhagen, Denmark, 255. DOI: https: //doi.org/10.1145/1841853.1841901

[76] UNDP (Ed.). 2016. Youth and the prospects for human development in a changing reality. United Nations Development Programme, Regional Bureau for Arab States, New York, NY.

[77] Natasha F. Veltri and Wafa Elgarah. 2009. The Role of National Cultural Differences in User Adoption of social Networking. Proceedings of the Southern Association for Information Systems Conference 2007, January 2007 (2009), 169174

[78] Steven Vertovec. 1999. Conceiving and researching transnationalism. Ethnic and Racial Studies 22, 2 (January 1999), 447-462. DOI: https://doi.org/10.1080/ 014198799329558

[79] Sarah Vieweg and Adam Hodges. 2016. Surveillance \& Modesty on Social Media: How Qataris Navigate Modernity and Maintain Tradition. Proceedings of the 19th ACM Conference on Computer-Supported Cooperative Work \& Social Computing CSCW'16 (2016), 526-537. DOI: https://doi.org/10.1145/2818048.2819966

[80] Frank E. Vogel. 2012. Shari'a in the Politics of Saudi Arabia. The Review of Faith \& International Affairs 10, 4 (December 2012), 18-27. DOI: https://doi.org/10.1080/ 15570274.2012 .739892

[81] Tanja Walsh, Piia Nurkka, and Rod Walsh. 2010. Cultural differences in smartphone user experience evaluation. In Proceedings of the 9th International Conference on Mobile and Ubiquitous Multimedia - MUM '10, ACM Press, Limassol, Cyprus, 1-9. DOI: https://doi.org/10.1145/1899475.1899499

[82] Yang Wang and Blase Ur. 2013. A Cross-Cultural Framework for Protecting User Privacy in Online Social Media. International World Wide Web Conference Committee (IW3C2) (2013), 1-8.

[83] Carla Willig. 2013. Introducing qualitative research in psychology (3. ed ed.). Open Univ. Press, Maidenhead.

[84] James Wynbrandt. 2010. A brief history of Saudi Arabia (2nd ed ed.). Facts On File, New York, NY.

[85] Tamara Yakaboski, Karla Perez-Velez, and Yousef Almutairi. 2017. Collectivists' Decision-Making: Saudi Arabian Graduate Students' Study Abroad Choices. Journal of International Students 7, 1 (January 2017), 94-112. DOI: https://doi.org/ $10.32674 /$ jis.v7i1.247 